\title{
Analysis of Head Injuries Due to Motorcycle Accidents Attended in Medical Teaching Institute (MTI), DHQ, Gomal Medical College (GMC), Dera Ismail Khan, Pakistan
}

\author{
SARFARAZ KHAN, ${ }^{1}$ SHAHID NAWAZ, ${ }^{2}$ FAKHAR HAYAT ${ }^{2}$ \\ SARAH REHMAN, ${ }^{2}$ NOOR SARDAR ${ }^{2}$ \\ ${ }^{1}$ Department of Neurosurgery, Kohat Institute of Medical Sciences (KIMS) Kohat - Pakistan \\ ${ }^{2}$ Medical Teaching Institution (MTI), District Headquarter (DHQ), Gomal Medical College (GMC), \\ Dera Ismail Khan - Pakistan
}

DOI: https://doi.org/10.36552/pjns.v23i3.357

\begin{abstract}
Objective: The consumption of motorbike is increasing in Asia. The aim of this study was to analyze the head injuries due to motorcycle accidents attended in the District Headquarter (DHQ), Dera Ismail Khan.
\end{abstract}

Material and Methods: All the age groups from both genders were part of our study. All the patients show reduced GCS with some sign of having abnormalities on Computed tomography (CT) brain were included in our eligibility criteria. Pedestrians, those died before hospital arrival, complain about any other type of injury other than a head injury, and not have proper admission in the hospital was excluded from the study.

Results: 478 patients were included in the current study. More than $44.14 \%$ of accidents were reported in patients aged 20 - 29 years. 441 (92.25\%) were men, and 381 (79.7\%) were driving themselves. Among 478 only 71 (14.85\%) were wearing a helmet. Almost 47.48\% of the accidents occurred on the weekend. 274 (57.32\%) patients reached the hospital within 5 hours after the accident. 218 (45.6\%) patients had a head injury. Brain edema was the most common CT abnormality 214 (44.8\%).

Conclusion: Mainly, the males were affected by a motorcycle accident and face head injury in the third decade of their life. The CT scan indicates brain edema as the most common findings. $45.6 \%$ of patients have a severe head injury and a mortality rate of $13.4 \%$ was reported.

Keywords: Road Traffic Injuries (RTIs), Road traffic accidents (RTAs).

\section{INTRODUCTION}

The aim of this study was to analyze the head injuries due to motorcycle accidents reported in the District Headquarter (DHQ) Hospital of D. I. Khan. In 2012, WHO mentioned that the main reason of death in people age ranged from $15-29$ was the motorcycle head injury. ${ }^{1}$ Motor vehicle accidents are a prominent reason for death among teenagers and youth. ${ }^{2}$ The road accidents lead to severe injuries. ${ }^{3}$ It is estimated that worldwide 8,56,000 road expiries occur annually. Among them, almost $74 \%$ occur in developing countries. ${ }^{4}$ Road Traffic Injuries (RTIs) are considered as the main reason for injuries and deaths around the world. According to some predictions, by 2020 it will become the third most common reason of death globally. ${ }^{5}$ People prefer to use two-wheeled motorbikes due to its small size and capability to move easily from the massy traffic. ${ }^{6}$ Motorbike accidents have become a major safety problem in the world. It may cause serious head injuries that result in casualties. ${ }^{7-9}$ Almost $61 \%$ of deaths in motorcycle accidents are due to head injuries. ${ }^{10}$ Use of helmet reduces the chances of head injuries to a great extent. ${ }^{11}$ Many studies proved the positive connection between the use of helmet and the reduction of head injuries and deaths among bike riders. The reported percentage 
of injuries varies from $60-88 \% .^{12,13}$

Studies proved that road traffic accidents (RTA) are responsible for $50 \%$ of deaths among motorbike users. ${ }^{14}$ The main reasons for these injuries in developing countries are the failure of motorcyclists to use helmets, over speeding, and not observing the traffic laws. ${ }^{15,16}$ The researchers have identified another reason for bike accidents in South and East Asian region i.e., the entanglement of loose garments in two or three-wheeler vehicles. ${ }^{17-20}$

In developed countries, the rate of injuries and casualties are comparatively low as compared to the developing countries. But still, the mortality rate due to motorbike accidents is twenty times more than other automobile accidents. ${ }^{21,22}$ The consumption of motorbike is increasing in Asia, e.g. only in Pakistan, in 2000 , there were 100,000 motorbike users, with two million increase annually. ${ }^{23}$ A $16 \%$ mortality rate is reported among motorcyclists. ${ }^{24}$

\section{MATERIALS AND METHODS}

\section{Study Design and Sampling}

This prospective, multi-centric study was conducted from November 2018 - June 2019. This study was initiated after approval from the research ethics committee. The data was collected from the MTI, DHQ, AND GMC hospitals of D.I. Khan of 478 patients was included in the study that complains about any head injury.

\section{Inclusion Criteria}

All the age groups from both genders were included in our study.

Patients with altered GCS along with Computed tomography (CT) brain abnormalities were included in our eligibility criteria.

The patients were treated according to the procedure in the hospital. They were evaluated according to the modern trauma life support guideline $^{25}$ and stabilized in the trauma room. After recovery, a thorough demographic history was obtained with the help of pre-designed Performa.

After taking their history, patients were referred for other relevant investigations like brain X-rays, CT scan brain, chest CT or chest X-ray, MRI or 3D CT.

In order to analyze the head injury, we categorized them into three groups i.e. severe, moderate, and mild, according to the GCS, GCS $3-8,9-12$, and $13-15$ respectively. Other than these, some threatening signs like loss of consciousness (LOC) > $25 \mathrm{~min}$, amnesia after a head injury, nausea, etc. were also recorded. The patients were discharged from Neurotrauma if their CT was normal, and GCS was unaltered.

\section{Exclusion Criteria}

Pedestrians, those who died before hospital arrival, complains other than head injury and those patients who were not admitted in the hospital were excluded from the study.

\section{Data Analysis}

The data was entered and analyzed using SPSS version 22. Frequency and percentage of tables were generated. The Chi-square test was applied and $\mathrm{P}<$ 0.05 was considered as statistically significant.

\section{RESULTS}

The 478 patients were included in the current study. In Table 1, the demographic details of the patients, factors related to injury, wearing a helmet or not, and the patients' status as driver or rider were compiled. The $211(44.14 \%)$ accidents were reported in patients of age 20-29 years. 441 (92.25\%) were men, and 381

Table 1: Demographic status of patients.

\begin{tabular}{|l|c|c|}
\hline Variables & Frequency (n) & Percentage (\%) \\
\hline Age & & \\
\hline $1-10$ & 9 & 1.9 \\
\hline $11-20$ & 211 & 17.1 \\
\hline $21-30$ & 74 & 15.41 \\
\hline $31-40$ & 51 & 10.61 \\
\hline $41-50$ & 30 & 6.22 \\
\hline $51-60$ & 21 & 4.4 \\
\hline $61-70$ & & \\
\hline Gender & 441 & 92.25 \\
\hline Male & 37 & 7.75 \\
\hline Female & 381 & 79.7 \\
\hline Patients' Status & 97 & 20.3 \\
\hline Driver & & \\
\hline Backseater & & \\
\hline
\end{tabular}


(79.7\%) were operating motorcycle themselves and remaining were the back-seaters.

Among 478, only $71(14.85 \%)$ were wearing a helmet. It was also observed that almost $47.48 \%$ of the accidents were happening on Saturdays and Sundays. The $274(57.32 \%)$ patients reached the hospital within 5 hours after the accident. The types of accident and other above-mentioned details are shown in Table 2.

Table 2: Important variables required for study.

\begin{tabular}{|l|c|c|}
\hline Helmet & Number & Percentage \\
\hline Yes & 71 & 14.85 \\
\hline No & 407 & 85.15 \\
\hline Type of Accidents & & \\
\hline Motorcycle to car & 149 & 31.1 \\
\hline Motorcycle to Truck & 121 & 25.3 \\
\hline Motorcycle to motorcycle & 54 & 11.2 \\
\hline Motorcycle to wall & 102 & 21.3 \\
\hline Motorcycle to others & 52 & 10.87 \\
\hline Arrival Time & & \\
\hline 1-5 hours & 274 & 57.32 \\
\hline 6-10 hours & 132 & 27.65 \\
\hline 11-15 hours & 54 & 11.29 \\
\hline 16-20 hours & 18 & 3.74 \\
\hline Accident Day & 251 & 52.52 \\
\hline $\begin{array}{l}\text { Working days } \\
\text { (Monday-Friday) }\end{array}$ & 227 & 47.48 \\
\hline Weekend (Saturday-Sunday) & & \\
\hline
\end{tabular}

Table 3 mentions the type of head injury on the basis of GCS. The $218(45.6 \%)$ patients lie in thesevere category of head injury. In Table 4, the

Table 3: Nature of head injury.

\begin{tabular}{|l|c|c|c|}
\hline $\begin{array}{l}\text { Kind of } \\
\text { Head Injury }\end{array}$ & GCS & Number & $\begin{array}{c}\text { Percentage } \\
(\mathbf{\%})\end{array}$ \\
\hline Severe & $3-8$ & 218 & 45.6 \\
\hline Moderate & $9-12$ & 154 & 32.2 \\
\hline Mild & $13-15$ & 106 & 22.2 \\
\hline
\end{tabular}

condition of patients head injury was compiled after CT scan. Brain edema had the largest share i.e. 214 $(44.8 \%)$.

Table 4: Findings of CT Scan.

\begin{tabular}{|l|c|c|}
\hline Findings of CT Brain & Frequency & $\begin{array}{c}\text { Percentage } \\
(\%)\end{array}$ \\
\hline Subdural hematoma & 53 & 11.1 \\
\hline Contusions & 117 & 24.5 \\
\hline Brain edema & 214 & 44.8 \\
\hline Epidural hematoma & 106 & 22.2 \\
\hline Pneumochpalaus & 61 & 12.8 \\
\hline $\begin{array}{l}\text { Traumatic Subarachnoid } \\
\text { hemorrhage }\end{array}$ & 83 & 17.4 \\
\hline Depressed skull fractures & 32 & 6.6 \\
\hline
\end{tabular}

Table 5 shows the outcome of Glasgow coma score. In level 5, the percentage of the patients was $209(43.7 \%)$. The use of helmets and GCS were found to be statistically significant $(p=0.03)$ factors in traumatic head injury (TBI) patients. The death was reported in 64 patients with a mortality rate of $13.4 \%$.

Table 5: The outcome of Glasgow scale.

\begin{tabular}{|c|c|c|}
\hline $\begin{array}{l}\text { Glasgow Outcome } \\
\text { Score (GOS) }\end{array}$ & Frequency & $\begin{array}{c}\text { Percentage } \\
(\boldsymbol{\%})\end{array}$ \\
\hline 5 & 209 & 43.7 \\
\hline 4 & 113 & 23.6 \\
\hline 3 & 88 & 18.4 \\
\hline 2 & 27 & 5.6 \\
\hline 1 & 41 & 8.6 \\
\hline
\end{tabular}

\section{DISCUSSION}

The use of motorcycle has increased globally, especially in developing countries like ours. Among all the injuries, head injury is most common. ${ }^{26}$ The current study analyzed that the affected population was of male member $441(92.25 \%)$ and was in the range of age group 21 - 30 years i.e., 211 (44.41\%). The study of Monk et al also proved the same. ${ }^{27}$ Literature showed the similar findings regarding the age group of 
$21-31$ years for the head injury cases. ${ }^{28,29}$ Few studies also mentioned that the age groups from $11-20$ to 31 - 40 were more affected than the other age groups. ${ }^{30,31}$

The two main effects of head injury are loss of memory and consciousness. For the best analysis, we divided it into three main categories of GCS i.e. severe, moderate, and mild. It was observed that if a person has GCS more than 13, he has more chances of abnormal radiological outcomes. ${ }^{32,33}$ As the results of our studies are a concern, we also have a significant number of patients in this category i.e. 106 (22.2\%) who show abnormal CT scan results.

The estimated time of patients was calculated in our study was $1-5$ hours. Most of the patients come without any ventilator facility. The reasons for late arrival were heavy traffic, non-availability of the ambulance, and weak traffic rules. These factors resulted in more deaths from traffic accidents. ${ }^{34}$ In developing countries, people do not know about the traffic rules and the importance of wearing a helmet in the two-wheeled vehicle. In our study, only 71 (14.85\%) patients used to wear helmets, and the remaining were not $407(85.15 \%)$. This observation was also consistent with some previous studies. ${ }^{35-37}$

The CT scan of all patients was done because of its importance as an early imaging technique within 24 hours ${ }^{38}$ and it detects pathologies and hematoma more accurately as compared to MRI. ${ }^{39}$ According to Papa et $\mathrm{al}^{40}$ and Leong et al., ${ }^{41}$ the CT scan is recommended for the patients presenting with a traumatic head injury. It is also suggested that a CT scan should be done if a patient of traumatic head injury shows any signs of nausea, loss of memory, and LOC. ${ }^{42,43}$ In our study, the CT scan was done if any above-mentioned factors were reported. We excluded patients with a normal CT scan.

In the current study, $6.6 \%$ of cases were having depressed skull fractures, $11.1 \%$ subdural hematomas, $22.2 \%$ epidural hematomas, $44.8 \%$ brain edema, $17.4 \%$ traumatic subarachnoid hemorrhages and $12.8 \%$ pneumocephalus. The findings of Leong et.al showed a great number of epidural hematoma with a $5 \%$ mortality rate. ${ }^{44}$ Our study showed a mortality rate of $13.4 \%$ quite similar to the study, which showed a $13.2 \%$ mortality. ${ }^{45}$ Nnadi et $\mathrm{al}^{46}$ showed that $21.6 \%$ of patients have brain edema, whereas, we reported it as $44.8 \%$. Zimmerman et al showed a brain edema as the common result of CT scan. ${ }^{47}$

\section{CONCLUSION}

Mainly, males were affected by motorcycle accidents and faced head injury in their third decade of their life. The CT scan indicated the brain edema as the most common findings. $45.6 \%$ of patients had a severe head injury with mortality rate of $13.4 \%$.

\section{Recommendations}

We suggested that the effective use of quality helmets can reduce the probability of losses of life and severe head injuries in the injured motorcyclists in Pakistan. Refining regulation and implementation might help avoid deaths and serious head injuries in Pakistan and in other countries. ${ }^{48,49}$

\section{Limitation of the Study}

This study was included the limited number of patients and a relatively shorter time duration. There is a need for study on a larger number of patients. The data from the trauma centers would present more significant results in detail.

\section{Additional Information}

Disclosures: Authors report no conflict of interest.

Human Subjects: Consent was obtained by all patients/ participants in this study.

\section{Conflicts of Interest:}

In compliance with the ICMJE uniform disclosure form, all authors declare the following:

Financial Relationships: All authors have declared that they have no financial relationships at present or within the previous three years with any organizations that might have an interest in the submitted work.

Other Relationships: All authors have declared that there are no other relationships or activities that could appear to have influenced the submitted work.

Address for Correspondence:
Dr. Shahid Nawaz
Assistant Professor \& Head
Department of Neurosurgery
MTI, DHQ Teaching Hospital
GMC, D. I. Khan
Email: nsgshahidkhattak2012@gmail.com

REFERENCES

1. WHO. WHO World Health Organization, Global status report on road safety, Switzerland, 2015. 
2. Smith GS tccBarss PG. Unintentional injuries in developing countries: the epidemiology of a neglected problem. Epidemiology Reviews, 2017; 13: 228-266.

3. Montag JA. Radical change in traffic law: Effects on fatalities in the Czech Republic. J Public Health (Oxford), 2016; 36 (4): 539-545.

4. World Bank. Investing in Health. World Development Report 1993, London: Oxford University Press. 1993

5. World Health organization. World report on road traffic injury prevention, Geneva: WHO, 2014.

6. Hurt, HH, Ouellet, JV, Thom, DR. Motorcycle accident cause factors and identification of countermeasures, traffic safety center, Los Angeles: University of Southern California, 2015.

7. Depreitere B, Van Lierde C, Maene S, et al. Bicyclerelated head injury: a study of 86 cases. Accid Anal Prev. 2017; 36: 561-7.

8. Mayrose J. The effects of a mandatory motorcycle helmet law on helmet use and injury patterns among motorcyclist fatalities. J Safety Res. 2018; 39: 429-32.

9. Peng Y, Vaidya N, Finnie R, et al. Universal motorcycle helmet laws to reduce injuries: a community guide systematic review. Am J Prev Med. 2017; 52: 820-32.

10. Ministry of Transportation and Communications. Traffic statistics of year 2014. Republic of China, 2015.

11. Chiu WT, Chu SF, Chang CK, et al. Implementation of a motorcycle helmet law in Taiwan and traffic deaths over 18 years. JAMA. 2016; 306: 267-8.

12. Amoros E, Chiron M, Martin JL, et al. Bicycle helmet wearing and the risk of head, face, and neck injury: a French case-control study based on a road trauma registry. Inj Prev. 2012; 18: 27-32.

13. Attewell RG, Glase K, McFadden M. Bicycle helmet efficacy: a meta-analysis. Accid Anal Prev. 2015; 33: 345-52.

14. Vafaee-Najar, A, Esmaeili, H, Ibrahimipour, $\mathrm{H}$. Motorcycle fatal accidents in Khorasan Razavi Province, Iran. Iran J Public Health, 2018; 39: 95-101.

15. Museru, LM, Mcharo, CN, Leshabari, MT. Road traffic accidents in Tanzania: a 10-year epidemiological appraisal. East Central Afr J Surg. 2017; 7: 23-26.

16. Galukande, M, Jombwe, J, Fualal, J. Boda-boda injures a health problem and the burden of disease in Uganda: a tertiary hospital survey. East Central Afr J Surg. 2015; 14: 33-37.

17. Agarwal, A., \& Agarwal, R. Faces of the spine care: Dupatta injuries. The Spine Journal, 2018; 8 (4): 703704.

18. Aggarwal, N.K., \& Agarwal, B.B. Accidental strangulation in a cycle rickshaw. Medicine Science and the Law, 2015; 38 (3): 263-265.

19. Agrawal, A., Ninave, S., Srivastava, T., Sunkara, A., \& Agrawal, S. Accidental unilateral and incomplete strangulation injury in a patient while traveling on a bicycle. Journal of Forensic and Legal Medicine, 2018; 16 (6): 350-351.

20. Chiu, C.K., Chan, C.Y., Saw, L.B., \& Kwan, M.K. Scarfrelated hangman's fracture: A case report. European Journal of Trauma and Emergency Surgery, 2015; 36: 180-182.

21. Peden, M. World report on road traffic injury prevention-summary, Geneva: World Health Organization, 2014.

22. Solagberu, BA, Ofoegbu, CK, Nasir, AA. Motorcycle injuries in a developing country and the vulnerability of riders, passengers, and pedestrians. Inj Prev. 2016; 12: 266-268.

23. Initial results of Pakistan's first road traffic injury surveillance project. Shamim S, Razzak JA, Jooma R, Khan U. Int J Inj Contr Saf Promot. 2017; 18: 213-217.

24. Traffic safety among motorcyclists in Norway: a study of subgroups and risk factors. Bjornskau T, Naevestad TO, Akhtar J. Accid Anal Prev. 2016; 49: 50-57.

25. American College of Surgeon. Advanced trauma life support, Chicago: Author, 1997.

26. Larke DD, Ward P, Bartle C, Truman W. In-depth Study of Motorcycle Accidents. Road Safety Research Report. 2014: 54.

27. Monk JP, Buckley R, Dyer D. Motorcycle-related trauma in Alberta: a sad and expensive story. Can J Surg. 2019; 52:235-240.

28. Shukla D, Devi BI: Mild traumatic brain injuries in adults. J Neurosc Rural Pract. 2016; 1 (2): 82-88.

29. Lee B, Newberg A. Neuroimaging in Traumatic Brain Imaging. Neuro Rx. 2015; 2 (2): 372-83.

30. Christian WJ, Carroll M, Meyer K, Vitaz TW, Franklin GA. Motorcycle helmets and head injuries in Kentucky, 1995-2000. J Ky Med Assoc. 2003; 101: 21.

31. Masson F et al.: Epidemiology of severe brain injuries: A prospective population-based study. J Trauma. 2017; 51 (3): 481-489.

32. Stevens JA, Dellinger AM: Motor vehicle and fall related deaths among older Americans 1990-98: Sex, race, and ethnic disparities. Inj Prev. 2012; 8 (4): 272275 .

33. Van HT, Singhasiv anon P, K aewkungw al J, Suriyawongpaisal P, Khai LH. Estimation of non-fatal road traffic injuries in Thai Nguyen, Vietnam using capture recaptures method. Southeast Asian J Trop Med Public Health, 2016; 37: 405.

34. Thurman D: Head Trauma: Basic, preclinical, and clinical directions. In: Miller L, Ayes R(ed). Head Trauma: Basic, Preclinical, and Clinical Directions. New York: John Wiley and Sons, 2018: 327-347.

35. Jinnah Postgraduate Medical Centre, Half Yearly Report Jan to Jun \& Half Yearly Comparison of 2008 to 2011. Road Traffic Injury Research \& Prevention Centre, 2011 Aug.

36. Hyder AA, Ghaffar A, Masood TI: Motor vehicle 
crashes in Pakistan: The emerging epidemic. Inj Prev. 2017; 6: 199-20.

37. Naddumba EK. A cross sectional retrospective study of boda injuries at Mulago Hospital in Kampala, Uganda. ECAJS. 2015; 9: 44-47.

38. Raja IA, Vohra AH. Ahmed M: Neurotrauma in Pakistan. World J Surg. 2017; 25: 1230-1237.

39. M. Richter, D. Otte, U. Lehmann et al. Head injury mechanisms in helmet-protected motorcyclists: prospective multicenter study, J Trauma-Injury, Infection and Critical Care, 2015; 51 (5): 949-958.

40. Papa L, et al. Performance of the Canadian CT Head Rule and the New Orleans Criteria for predicting any traumatic intracranial injury on computed tomography in a United States Level I trauma center. Acad Emerg Med. 2018; 19 (1): 2-10.

41. Stippler M, et al. Utility of routine follow-up head CT scanning after mild traumatic brain injury: A systematic review of the literature. Emerg Med J. 2016; 29 (7): 528-532.

42. Sharif-Alhoseini M, Khodadadi H, Chardoli M, Rahimi Movaghar V: Indications for brain computed tomography scan after minor head injury. J Emerg Trauma Shock, 2017; 4 (4): 472-476.

43. Bainbridge J, Khirwadkar H, Hourihan MD: Vomiting is this a good indication for CT head scans in patients with minor head injury? Br J Radiol. 2017; 85 (1010): 183-186.

44. Leong LB, Sukarom S, Vasu A, Hian LG: Identifying predictors of an abnormal computed tomographic scan among patients with a head injury and a Glasgow Coma Scale of 15. Eur J Emerg Med Epub ahead of print, 2018.

45. J. Hitimana, M. Perez, A. Kinasha, and I. Kakande. "Clinical presentation and outcome of neurosurgical conditions at Butare teaching hospital, Rwanda," East Central Afr J Surg. 2019; Vol. 14, No. 1: pp. 50-56.

46. Nnadi MON, Bankole OB, Fente BG. Motorcycle Related Traumatic Brain Injuries: Helmet Use and Treatment Outcome. J Neurosci. 2015; 2015: 696-787.

47. Zimmerman, Robert A., et al. "Computed Tomography of Pediatric Head Trauma: Acute General Cerebral Swelling 1." Radiology, 2017; 126.2: 403-408.

48. Watson GS, Zador PL, Wilks. The repeal of helmet use laws and increased motorcyclist mortality in the United States, 1975-1978. Am J Public Health, 1980; 70: 579585.

49. Tsai M-C, Hemenway D. Effect of the mandatory helmet law in Taiwan. Inj Prev. 2015; 5: 290-291.

\begin{tabular}{|c|c|c|c|}
\hline \multicolumn{4}{|c|}{ AUTHORSHIP AND CONTRIBUTION DECLARATION } \\
\hline Sr.\# & Author's Full Name & Intellectual/Contribution to Paper in Terms of: & \multirow{3}{*}{$\begin{array}{l}\text { Signature by the } \\
\text { author(s) } \\
\text { Slehan }\end{array}$} \\
\hline 1. & $\begin{array}{l}\text { Sarfaraz Khan } \\
\text { (Main/Principal Author). }\end{array}$ & \multirow{6}{*}{$\begin{array}{l}\text { 2. Wrote Discussion } \\
\text { 3. Analysis of data, References and interpretation } \\
\text { of results etc. } \\
\text { 4. Literature review and manuscript writing and } \\
\text { data Calculations }\end{array}$} & \\
\hline 2 & Shahid Nawaz & & \\
\hline 2. & (2nd Author) & & Apram \\
\hline 3. & $\begin{array}{l}\text { Fakhar Hayat } \\
\text { (3rd Author) }\end{array}$ & & falcha \\
\hline 4. & $\begin{array}{l}\text { Sarah Rehman } \\
\text { (4th Author) }\end{array}$ & & $\begin{array}{l}\text { SrRehme } \\
\text { Nisendar }\end{array}$ \\
\hline 5. & $\begin{array}{l}\text { Noor Sardar } \\
\text { (5th Author) }\end{array}$ & & \\
\hline
\end{tabular}

Date of Submission: 25-07-2019

Date of Revision: 10-08-2019

Date of Online Publishing: 25-09-2019

Date of Print: 30-09-2019 